\title{
PREDIKSI EROSI DAN ARAHAN PENGGUNAAN LAHAN DAERAH ALIRAN SUNGAI YEH LEH PROVINSI BALI
}

\author{
Ni Made Ayu Ratna Sari ${ }^{\left.1^{*}\right)}$, I Wayan Sandi Adnyana ${ }^{2)}$, I Nyoman Merit ${ }^{3)}$ \\ 1) Balai Pengelolaan Daerah Aliran Sungai dan Hutan Lindung Unda Anyar \\ ${ }^{2)}$ Fakultas Pertanian, Universitas Udayana \\ ${ }^{3)}$ Prodi Ilmu Lingkungan, Universitas Udayana \\ *Email: ratnadika@yahoo.co.id
}

\section{ABSTRACT \\ PREDICTION EROSION AND PROPOSED LAND USE YEH LEH WATERSHED BALI PROVINCE}

\begin{abstract}
Erosion in the watershed generally occurs due to land use that ignores the rules of soil and water conservation. There is much activity carried out by people living on land in the Yeh Leh watershed area, which makes the level of dependence is very enormous. The erosion forecast is using the USLE (Universal Soil Loss Equation) to estimate the erosion swift occurs and to obtain illustration in determining the precise soil and water measures in a region. The determination of land capability classification is using Arsyad's method (1989) in which to classify the land ability by classifying the land ability class based on the value of land limiting factors, which then adjusted to the criteria of classification of land capability. The land use directional determination is applying the scoring method where combining field slope factor, soil sensitivity to erosion and daily rainfall intensity. The erosion level of the YehLeh watershed area is categorized as mild to very severe. A very light erosion level as large as 515 ha (21.01\%), with the land use in the form of irrigated rice field and forest. The severe erosion level as large as $990.02 \mathrm{ha}(40.40 \%)$ with land use in the form of plantations. The very heavy erosion level as large as $945.82 \mathrm{ha}(38.59 \%)$ with land use in the form of plantations. The classification of land capability in the YehLeh watershed area consists of 5 classes of land abilities: class II of 115,22 ha (4.70\%), class III of 533.95 ha (21.79\%), class IV of 423.61 (17.28\%), Class VI of $1,102.03$ ha (44.97\%), and Class VII of 276.03 ha (11.26\%), with some limiting factors for instance, soil texture, erosion and drainage. Proposed land use in the YehLeh watershed area use for forest areas is as protected forest of 456.49 ha (18.63\%). Proposed land use outside of the forest area consist of 58.51 ha (2.39\%) of seasonal crops, annual cultivation area of 990.02 ha (40.40\%) and buffer area of $945.82(38.59 \%)$.
\end{abstract}

Keywords: watershed, erosion, land capability classification, proposed land use.

\section{PENDAHULUAN}

Pemanfaatan lahan menyebabkan perubahan tata guna lahan di suatu wilayah. Perubahan tata guna lahan seringkali tidak disertai dengan tindakan pencegahan kerusakan lahan, sehingga lahan semakin terdegradasi. Salah satu bentuk kerusakan lahan yang dapat dilihat saat ini yaitu berupa erosi yang diakibatkan adanya penggunaan lahan yang tidak tepat, sehingga mengakibatkan menurunnya kualitas tanah dan air. Penyebab terjadinya erosi di suatu lahan adalah penggunaan lahan yang tidak sesuai dengan peruntukannya dan tidak adanya tindakan konservasi tanah dan air yang bisa menekan ataupun mencegah erosi yang mungkin terjadi.

Daerah aliran sungai (DAS) adalah suatu wilayah daratan yang secara topografik dibatasi oleh punggung-punggung gunung yang menampung dan menyimpan air hujan untuk kemudian menyalurkannya ke laut melalui sungai utama. Wilayah daratan tersebut dinamakan daerah tangkapan air (catchment area) yang merupakan suatu ekosistem dengan unsur utamanya terdiri atas sumberdaya alam (tanah, air, dan vegetasi) dan sumberdaya manusia sebagai pemanfaat sumberdaya alam (Asdak, 2010). Namun penggunaan lahan yang berkaitan erat dengan aktivitas manusia menyebabkan keseimbangan ekosistem DAS terganggu. Eksploitasi DAS menimbulkan masalah : 1) banjir di musim hujan dan kekeringan di musim kemarau, 2)penurunan debit air sungai, 3)erosi dan sedimentasi, 4) longsor.

Erosi di DAS umumnya terjadi karena pemanfaatan lahan yang tidak mengindahkan kaidah konservasi tanah dan air. Erosi di suatu lahan menyebabkan hilangnya lapisan atas tanah yang subur untuk menyangga pertumbuhan tanaman (Tan, 1991). Untuk mempertahankan kelestarian produktivitas tanah maka dapat dilakukan hal - hal yang dapat mencegah agar erosi yang terjadi tidak melebihi batas yang dapat ditoleransikan melalui upaya rehabilitasi dan konservasi tanah.

DAS Yeh Leh secara administrasi meliputi Kabupaten Buleleng (Kecamatan Busungbiu), Kabupaten Jembrana (Kecamatan Pekutatan), dan Kabupaten Tabanan (Kecamatan Selemadegdan 
Selemadeg Barat) dengan luas wilayah 2.450,84 ha,yang terdiri dari bentuk lahan vulkanik dan fluvial, dan penggunaan lahan yang beragam, baik itu hutan, kebun campuran, sawah, dan pemukiman. Terjadi banyak aktivitas yang dilakukan oleh penduduk yang tinggal pada lahan di wilayah Daerah Aliran Sungai Yeh Leh, sehingga tingkat ketergantungan pada lahan sangat besar. Ketergantungan yang besar pada lahan, dapat menyebabkan adanya alih fungsi lahan yang dapat memicu terjadinya erosi. Adanya alih fungsi lahan juga akan berdampak pada kualitas kemampuan lahan yang ada karena tidak sesuai dengan peruntukannya. Oleh karena itu penting untuk mengetahui tentang prediksi erosi yang terjadi jika suatu lahan mengalami alih fungsi.Hal inilah yang membuat ketertarikan minat dari penulis untuk memilih DAS Yeh Leh sebagai lokasi penelitian.

Penelitian ini dilakukan untuk memproleh hasil prediksi erosi,klasifikasi kemampuan lahan dan arahan penggunaan lahandi wilayah DAS Yeh Leh. Melalui penelitian yang dilakukan ini, diharapkan akan dapat mengetahui tingkat erosi yang terjadi, mengklasifikasi kemampuan lahan yang ada, serta dapat menghasilkan arahan penggunaan lahan danperencanaan konservasi tanah dan air di DAS Yeh Leh.

\section{METODOLOGI}

Penelitian ini dilaksanakan di Daerah Aliran Sungai Yeh Leh yang secara astronomis terletak pada $08^{\circ} 30,5^{\prime} 15^{\prime \prime}$ BT sampai $115^{\circ} 5,5^{\prime} 45^{\prime \prime}$ BT. Secara administratif meliputi Kabupaten Buleleng, Jembrana, dan Tabanan dengan luas wilayah $2.450,84$ ha. Waktu pelaksanaan penelitian yaitu dari bulan Februari - April 2017.

Tabel 1. Satuan Unit Lahan Daerah Penelitian

\begin{tabular}{cccc}
\hline $\begin{array}{c}\text { No Unit } \\
\text { Lahan }\end{array}$ & $\begin{array}{c}\text { Penggunaan } \\
\text { Lahan }\end{array}$ & $\begin{array}{c}\text { Kemiringan } \\
\text { Lereng(\%) }\end{array}$ & $\begin{array}{c}\text { Jenis } \\
\text { Tanah }\end{array}$ \\
\hline 1 & Sawah & $3-8$ & Latosol \\
2 & Perkebunan & $3-8$ & Latosol \\
3 & Perkebunan & $8-15$ & Latosol \\
4 & Perkebunan & $15-30$ & Latosol \\
5 & Perkebunan & $30-45$ & Latosol \\
6 & Hutan & $15-30$ & Latosol \\
7 & Hutan & $30-45$ & Latosol \\
8 & Hutan & $45-65$ & Latosol \\
9 & Perkebunan & $30-45$ & Regosol \\
\hline
\end{tabular}

Kegiatan yang dilakukan dalam penelitian ini yang pertama adalah mendapatkan peta unit lahan daerah penelitian yaitu dengan menumpangtindihkan peta jenis tanah, peta kemiringan lereng dan peta penggunaan lahan sehingga didapatkan peta unit lahan. Selanjutnya ditentukan titik sampel yang akan diambil sesuai dengan peta yang telah ditumpangtindihkan baik itu kemiringan lereng, jenis tanah dan penggunaan lahan. Setelah pengumpulan data selesai dan data telah didapatkan maka selanjutnya dilakukan analisis data yang menyangkut prediksi erosi, klasifikasi kemampuan lahan dan arahan penggunaan lahan dengan metode yang telah ditentukan.

Dalam penelitian ini untuk memprediksi erosi menggunakan rumusan USLE yang telah dikembangkanoleh Wischmeier dan Smith (1978), maka diperlukan analisis beberapa faktor, yaitu erosivitas hujan (R), erodibilitas tanah (K), panjang dan kemiringan lereng (LS), pengelolaan tanaman (C) dan pengelolaan tanah (P). Dari pengaruh kelima faktor tersebut maka akan diperoleh nilai dari rumusan USLE untuk menentukan seberapa besar dan kelas bahaya erosi yang terjadi, yang selanjutnya digunakan dalam penentuan perencanaan konservasi tanah dan air. Klasifikasi kemampuan lahan menggunakan metodeArsyad (1989) yaitu dengan memperhitungkan nilai pada masing - masing faktor pembatas, seperti faktor pembatas kemiringan lereng, tingkat bahaya erosi, kedalaman efektif, tekstur, permeabilitas, drainase, batuan dan ancaman banjiryang selanjutnya disesuaikan dengan tabel klasifikasi kemampuan lahan yang ada, sehingga diperoleh pengkelasan kemampuan lahan dari I - VIII.

Arahan penggunaan lahan menggunakan metode skoring yang berdasarkan atas SK Menteri Pertanian Nomor 837/Kpts/Um/11/1980. Penggunaan metode ini dipengaruhi oleh tiga faktor yaitu faktor lereng lapangan, faktor kepekaan jenis tanah terhadap erosi dan faktor intensitas hujan harian rata-rata. Dari penjumlahan ketiga faktor tersebut untuk di luar kawasan hutan akan menentukan nilai dari kawasan lindung dengan skor $>175$, kawasan penyangga dengan skor antara 125 - 174, dan kawasan budidaya tahunan dan semusim dengan skor $<124$, sedangkan untuk di dalam kawasan hutan akan menentukan nilai dari kawasan hutan lindung dengan skor $>175$, hutan produksi dengan skor antara 125-174 dan hutan suaka alam dan wisata ditetapkan berdasarkan kepentingan kebudayaan, ilmu pengetahuan, pelestarian plasma nutfah dan rekreasi.

\section{HASIL DAN PEMBAHASAN}

\subsection{Prediksi Erosi}

Data yang diperoleh dari stasiun pengamat curah hujan yang ada di daerah penelitian, yaitu data curah hujan, hari hujan dan curah hujan maksimum dalam 24 jam. Stasiun pengamat curah hujan yang digunakan pada daerah penelitian meliputi 3 stasiun pengamat curah hujan, yaitu stasiun Busungbiu di Kabupaten Buleleng, stasiun Selemadeg Barat di Kabupaten Tabanan dan stasiun Pulukandi 
Kabupaten Jembrana. Data curah hujan, hari hujan dan curah hujan maksimum dalam 24 jam yang digunakan adalah selama 10 tahun terakhir dari tahun 2007-2016. Nilai erosivitas hujan dipengaruhi oleh curah hujan, hari hujan, dan curah hujan maksimum dalam 24 jam. Hasil perhitungan dengan menggunakan rumus Bols (1978) diperoleh nilai yang bervariasi antara stasiun pencatat curah hujan yang satu dengan yang lainnya yang disebabkan oleh adanya curah hujan dan intensitas hujan yang berbeda beda di masing-masing stasiun curah hujan. Nilai rata - rata erosivitas hujan dari ketiga stasiun yang digunakan untuk wilayah penelitian menunjukkan bahwa nilai rata-rata dari erosivitas hujan ( R) tahunan yaitu sebesar 2217,11 ton $/ \mathrm{ha} / \mathrm{cm}$.

Faktor erodibilitas tanah (K) dipengaruhi oleh empat faktor yaitu tekstur, struktur, kandungan bahan organik, dan permeabilitas tanah. Perbedaan nilai erodibilitas tanah (K) merupakan salah satu faktor penyebab terjadinya perbedaan erosi pada masing-masing unit lahan pada wilayah penelitian. Dilihat dari kelas struktur tanah pada wilayah penelitian pada setiap unit lahannya cukup bervariasi yaitu dari kelas struktur sangat halus (unit lahan 7 dan 8) dan kelas struktur menggumpal (unit lahan 1,2,3,4,5,6, dan 9). Hasil perhitungan mengenai nilai erodibilitas tanah (K) pada wilayah penelitian menunjukkan bahwa unit lahan 4 memiliki nilai erodibilitas yang paling rendah, yaitu 0,17 . Unit lahan $1,2,5,6$, dan 8 memiliki nilai erodibilitas sedang dengan nilai $0,21-0,27$. Unit lahan 3, 7 dan 9 memiliki nilai erodibilitas agak tinggi yaitu $0,35 \mathrm{~cm} / \mathrm{jam}-0,39 \mathrm{~cm} / \mathrm{jam}$.

Faktor panjang dan kemiringan lereng (LS) sangat ditentukan oleh besarnya kemiringan lereng dan panjang lereng suatu wilayah. Berdasarkan hasil pengamatan dan pengukuran di lokasi penelitian menunjukkan panjang kereng berkisar dari 18-49 meter, sedangkan untuk kemiringan lerengnya berkisar dari $5-56 \%$. Untuk hasil perhitungan faktor panjang dan kemiringan lereng (LS) di wilayah penelitian menunjukkan nilai terendah pada unit lahan 2 sebesar 1,42 dan nilai tertinggi pada unit lahan 8 sebesar 15,47 .
Dalam menentukan nilai pengelolaan tanaman dan pengelolaan tanah dilakukan dengan melakukan pengamatan langsung di lapangan. Hasil penelitian menunjukkan bahwa nilai faktor pengelolaan tanaman $(\mathrm{C})$ pada setiap unit lahan yang ada dengan penggunaan lahan berupa sawah irigasi, perkebunan dan hutan alam. Hasil pengelolaan tanaman ( C ) berkisar antara 0,001 sampai 0,5 dan untuk nilai pengelolaan tanah $(\mathrm{P})$ berkisar antara 0,15 sampai 1,00 . Nilai gabungan pengelolaan tanaman dengan tindakan konservasi tanah ( $\mathrm{CP}$ ) berkisar antara 0,001 sampai 0,40 . Hasil pengamatan dan penyesuaian nilai CP pada lokasi penelitian menunjukkan bahwa nilai berkisar antara 0,001 0,175 . Untuk nilai faktor pengelolaan tanaman (C) dan pengelolaan tanah $(\mathrm{P})$ dilakukan melalui pengamatan langsung di lapangan dan menyesuaikan dengan pedoman nilai $\mathrm{CP}$ yang sudah ada (lampiran 1 dan 2). Nilai CP paling rendah yaitu pada unit lahan 6,7, dan 8 sebesar 0,001 dengan jenis penggunaan lahan hutan alam serasah tinggi namun tanpa adanya tindakan konservasi. Nilai CP tertinggi yaitu pada unit lahan 5 sebesar 0,175 dengan jenis penggunaan lahan perkebunan serasah sedang dan teras bangku konstruksi buruk.

Untuk memprediksi besarnya erosi yang terjadi di wilayah penelitian yaitu menggunakan rumus USLE yang dikembangkan oleh Wischmeier dan Smith (1978) yaitu nilai prediksi erosi (A) merupakan hasil kali dari faktor R, K, LS, C dan P. Berikut hasil perhitungan erosi rata - rata tahunan pada setiap unit lahan yang ada di wilayah penelitian (Tabel 2).

Berdasarkan hasil perhitungan menggunakan rumus USLE diperoleh nilai prediksi erosi (A) di wilayah DAS Yeh Leh berkisar antara 1,89 ton/ha/ tahun sampai 866,35 ton/ha/tahun, dengan kriteria ringan sampai sangat berat. Untuk kategori erosi ringan terjadi pada unit lahan 1,6, 7, dan 8 dengan luas 515 ha atau $21,01 \%$ dari luas wilayah penelitian. Untuk kategori erosi berat terjadi pada unit lahan 2, 3, 4 dan 9 dengan luas 990,02 ha atau 40,40\% dari luas wilayah penelitian. Erosi sangat berat

Tabel 2.Prediksi Erosi Rata - Rata Tahunan di DAS Yeh Leh

\begin{tabular}{|c|c|c|c|c|c|c|c|}
\hline \multirow{2}{*}{$\begin{array}{l}\text { No. Unit } \\
\text { Lahan }\end{array}$} & \multirow[b]{2}{*}{$\mathbf{R}$} & \multicolumn{3}{|c|}{ Nilai } & & \multirow{2}{*}{$\begin{array}{l}\text { Prediksi Erosi (A) } \\
\text { (ton/ha/thn) }\end{array}$} & \multirow{2}{*}{ Tingkat Erosi } \\
\hline & & $\mathrm{K}$ & LS & C & $\mathbf{P}$ & & \\
\hline 1 & 2217,11 & 0,25 & 2,28 & 0,01 & 0,15 & 1,89 & Ringan \\
\hline 2 & 2217,11 & 0,26 & 1,42 & 0,5 & 0,40 & 163,71 & Berat \\
\hline 3 & 2217,11 & 0,36 & 2,59 & 0,1 & 0,40 & 82,69 & Berat \\
\hline 4 & 2217,11 & 0,17 & 6,50 & 0,1 & 0,40 & 98,00 & Berat \\
\hline 5 & 2217,11 & 0,27 & 8,27 & 0,5 & 0,35 & 866,35 & Sangat berat \\
\hline 6 & 2217,11 & 0,21 & 6,29 & 0,001 & 1,00 & 2,93 & Ringan \\
\hline 7 & 2217,11 & 0,39 & 13,70 & 0,001 & 1,00 & 11,85 & Ringan \\
\hline 8 & 2217,11 & 0,23 & 15,47 & 0,001 & 1,00 & 7,89 & Ringan \\
\hline 9 & 2217,11 & 0,35 & 2,15 & 0,1 & 0,40 & 63,01 & Berat \\
\hline
\end{tabular}


terjadi pada unit lahan 5 dengan luas 945,82 ha atau $38,59 \%$ dari luas wilayah penelitian.

Rendahnya nilai prediksi erosi pada unit lahan $1,6,7$, dan 8, dapat disebabkan oleh beberapa faktor adalah memiliki nilai $\mathrm{C}$ dan $\mathrm{P}$ yang kecil, melalui pengamatan di lokasi pada unit lahan 1 adalah sawah irigasi dengan konstruksi sedang, bahwa penerapan konservasi berupa teras konstruksi sedang dapat mencegah terjadinya aliran permukaan serta didukung pula oleh nilai LS yang kecil karena kemiringan pada unit lahan 1 sebesar $7 \%$. Pada unit lahan 6, 7, dan 8 adalah hutan alami dengan serasah yang tinggi. Pada suatu penggunaan lahan yang memiliki serasah yang tinggi menunjukkan kerapatan tegakan yang cukup tinggi, sehingga keberadaan tajuk yang rapat dapat melindungi dari jatuhnya air hujan secara langsung ke tanah dan serasah yang banyak melindungi permukaan tanah dari aliran permukaan. Dengan adanya tanaman yang banyak pula, tentunya akar tanaman pun cukup banyak yang mampu menyerap air masuk ke dalam tanah sehingga akar tanaman merupakan faktor penunjang yang penting dalam pengendalian erosi (Rahim, 2003).

Untuk kategori erosi berat terjadi pada unit lahan 2, 3, 4 dan 9 seluas 990,02 ha (40,40 \%) dengan penggunaan lahan perkebunan dan penggunaan teras tradisional. Nilai erosi berat disebabkan karena nilai LS dan CP yang besar dan adanya ketidaksesuaian antara jenis penutup tanah dengan tindakan konservasi tanah. Penggunaan teras tradisional untuk kemiringan antara $24 \%-56 \%$ memberikan peluang aliran permukaan dapat merusak permukaan tanah dan memperbesar laju erosi.Hasil perhitungan erosi pada Tabel 5.8 menunjukkan nilai kedalaman tanah, sub grup tanah, faktor kedalaman tanah, umur guna, dan berat volume tanah. Dari hasil perhitungan didapatkan bahwa tingkat erosi yang dapat ditoleransikan pada lokasi penelitian dengan nilai terbesar pada unit lahan 6 yaitu 37,35 ton/ha/tahun sedangkan untuk nilai terkecil berada pada unit lahan 3 yaitu 23,32 ton/ha/tahun.
Berdasarkan hasil pengamatan di lapangan serta hasil analisis perhitungan prediksi erosi yang terjadi saat ini dengan erosi yang dapat ditoleransikan, berikut ini akan dirumuskan mengenai alternatif perencanaan penggunaan lahan dan konservasi tanah dan air di wilayah DAS Yeh Leh (Tabel 4)

Pada unit lahan 2 penggunaan lahan saat ini adalah perkebunan dengan serasah sedang dan tindakan konservasi tanah berupa teras tradisional dengan kemiringan lereng $5 \%$. Alternatif perencanaan konservasi tanah dan air dilakukan dengan mengubah faktor pengelolaan tanah yaitu dari teras bangku menjadi teras bangku konstruksi baik, melakukan penanaman menurut kontur pada kemiringan $0-8 \%$, serta penanaman strip rumput. Penurunan nilai erosi terjadi setelah dilakukannya tindakan konservasi tanah dari nilai erosi sebesar 163,71 ton/ha/tahun menjadi 12,28 ton/ha/tahun sehingga nilai tersebut sudah menjadi lebih kecil dari nilai erosi yang ditoleransikan pada unit lahan 2 sebesar 30,92 ton/ha/tahun.

Pada unit lahan 3 penggunaan lahan saat ini adalah perkebunan dengan serasah tinggi dan tindakan konservasi tanah berupa teras tradisional dengan kemiringan lereng $13 \%$. Alternatif perencanaan konservasi tanah dan air dilakukan dengan mengubah faktor pengelolaan tanah $(\mathrm{P})$ yaitu dari teras tradisional menjadi teras bangku konstruksi sedang dan penanaman strip rumput. Penurunan nilai erosi terjadi setelah dilakukannya tindakan konservasi tanah dari nilai erosi sebesar 82,69 ton/ha/tahun menjadi 12,40 ton/ha/tahun sehingga nilai tersebut sudah menjadi lebih kecil dari nilai erosi yang ditoleransikan yaitu 24,53 ton/ha/ tahun.

Pada unit lahan 4 penggunaan lahan saat ini adalah perkebunan dengan serasah tinggi dan tindakan konservasi tanah berupa teras tradisional dengan kemiringan lereng $27 \%$. Alternatif perencanaan konservasi tanah dan air dilakukan dengan mengubah faktor pengelolaan tanah yaitu dari teras tradisional menjadi teras bangku konstruksi baik dan melakukan penanaman

Tabel 3. Erosi yang Dapat Ditoleransikan (T) di DAS Yeh Leh

\begin{tabular}{|c|c|c|c|c|c|c|}
\hline $\begin{array}{l}\text { No. Unit } \\
\text { Lahan }\end{array}$ & $\begin{array}{l}\text { Kedalaman } \\
\text { Tanah(mm) }\end{array}$ & $\begin{array}{l}\text { Sub Grup } \\
\text { Tanah }\end{array}$ & $\begin{array}{c}\text { Faktor } \\
\text { Kedalaman }\end{array}$ & $\begin{array}{c}\text { Umur Guna } \\
\text { Tanah (Tahun) }\end{array}$ & $\begin{array}{l}\text { Berat Volume } \\
\left(\mathrm{gr} / \mathrm{cm}^{3}\right)\end{array}$ & $\begin{array}{c}\text { Erosi yang Dapat } \\
\text { Ditoleransikan (T) } \\
\text { (ton/ha/thn) }\end{array}$ \\
\hline 1 & 600 & Aquept & 0,95 & 300 & 1,327 & 25,21 \\
\hline 2 & 650 & Tropept & 1,00 & 300 & 1,427 & 30,92 \\
\hline 3 & 650 & Tropept & 1,00 & 300 & 1,132 & 24,53 \\
\hline 4 & 700 & Tropept & 1,00 & 300 & 1,158 & 27,02 \\
\hline 5 & 700 & Tropept & 1,00 & 300 & 1,250 & 29,17 \\
\hline 6 & 750 & Tropept & 1,00 & 300 & 1,576 & 39,40 \\
\hline 7 & 750 & Tropept & 1,00 & 300 & 1,234 & 30,85 \\
\hline 8 & 750 & Tropept & 1,00 & 300 & 1,296 & 32,40 \\
\hline 9 & 650 & Tropept & 1,00 & 300 & 1,405 & 30,44 \\
\hline
\end{tabular}


Tabel 4. Perencanaan Penggunaan Lahan dan Konservasi Tanah dan Air di DAS Yeh Leh

\begin{tabular}{|c|c|c|c|c|c|c|c|}
\hline $\begin{array}{l}\text { No Unit } \\
\text { Lahan }\end{array}$ & $\begin{array}{l}\text { Kondisi Lahan } \\
\text { Saat ini }\end{array}$ & $\begin{array}{l}\text { Alternatif Penggunaan } \\
\text { Lahan dan Konservasi } \\
\text { Tanah dan Air }\end{array}$ & $\begin{array}{c}\text { Nilai } \\
\text { Faktor C }\end{array}$ & $\begin{array}{c}\text { Nilai } \\
\text { Faktor P }\end{array}$ & $\begin{array}{l}\text { BesarErosi } \\
\text { Sebelum } \\
\text { Perencanaan } \\
\text { (ton/ha/tahun) }\end{array}$ & $\begin{array}{l}\text { Besar Erosi } \\
\text { Setelah } \\
\text { Perencanaan } \\
\text { (ton/ha/tahun) }\end{array}$ & $\begin{array}{c}\text { Erosi yang } \\
\text { Dapat } \\
\text { Ditoleransikan (T) } \\
\text { (ton/ha/tahun) }\end{array}$ \\
\hline 2 & $\begin{array}{l}\text { Perkebunan dengan } \\
\text { serasah sedang, kemi- } \\
\text { ringan lereng } 5 \% \text {, teras } \\
\text { tradisional. }\end{array}$ & $\begin{array}{l}\text { Perkebunan kerapatan } \\
\text { sedang, teras bangku } \\
\text { konstruksi sedang } \\
\text { dengan penanaman menurut } \\
\text { kontur pada kemiringan } \\
0-8 \% \text {, penanaman } \\
\text { strip rumput }\end{array}$ & 0,5 & 0,03 & 163,71 & 12,28 & 30,92 \\
\hline 3 & $\begin{array}{l}\text { Perkebunan dengan } \\
\text { serasah tinggi, kemi- } \\
\text { ringan lereng } 13 \% \text {, } \\
\text { teras tradisional. }\end{array}$ & $\begin{array}{l}\text { Perkebunan dengan kera- } \\
\text { patan tinggi, teras bangku } \\
\text { konstruksi sedang, pena- } \\
\text { naman strip rumput }\end{array}$ & 0,1 & 0.06 & 82,69 & 12,40 & 24,53 \\
\hline 4 & $\begin{array}{l}\text { Perkebunan dengan } \\
\text { serasah tinggi, kemi- } \\
\text { ringan lereng } 27 \% \text {, } \\
\text { teras tradisional }\end{array}$ & $\begin{array}{l}\text { Perkebunan dengan kera- } \\
\text { patan tinggi, teras bangku } \\
\text { konstruksi baik, penanaman } \\
\text { menurut kontur pada } \\
\text { kemiringan }>20 \%\end{array}$ & 0,1 & 0,04 & 98,00 & 8,82 & 27,02 \\
\hline 5 & $\begin{array}{l}\text { Perkebunan dengan } \\
\text { serasah sedang, kemi- } \\
\text { ringan lereng } 44 \% \text {, } \\
\text { teras tradisional }\end{array}$ & $\begin{array}{l}\text { Kebun campuran, tajuk ber- } \\
\text { tingkat, penutup tanah } \\
\text { bervariasi dengan kerapatan } \\
\text { tinggi, teras bangku } \\
\text { konstruksi sedang, } \\
\text { penanaman strip rumput }\end{array}$ & 0,1 & 0,006 & 866,35 & 2,97 & 29,17 \\
\hline 9 & $\begin{array}{l}\text { Perkebunan dengan } \\
\text { serasah tinggi, kemi- } \\
\text { ringan lereng } 5 \% \text {, } \\
\text { teras tradisional }\end{array}$ & $\begin{array}{l}\text { Perkebunan dengan kera- } \\
\text { patan tinggi, teras bangku } \\
\text { konstruksi sedang, } \\
\text { penanaman menurut kontur } \\
\text { pada kemiringan } 9-20 \%\end{array}$ & 0,1 & 0,11 & 63,01 & 17,72 & 30,44 \\
\hline
\end{tabular}

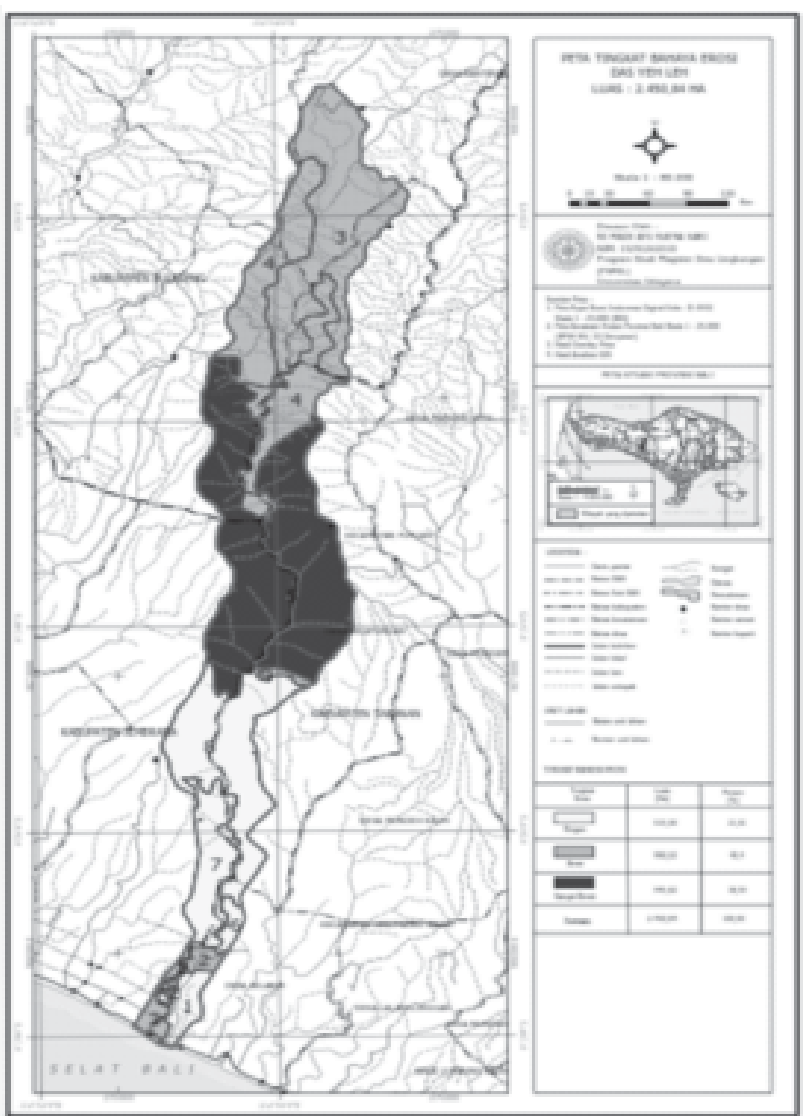

Gambar 1.

Peta Tingkat Bahaya Erosi DAS Yeh Leh

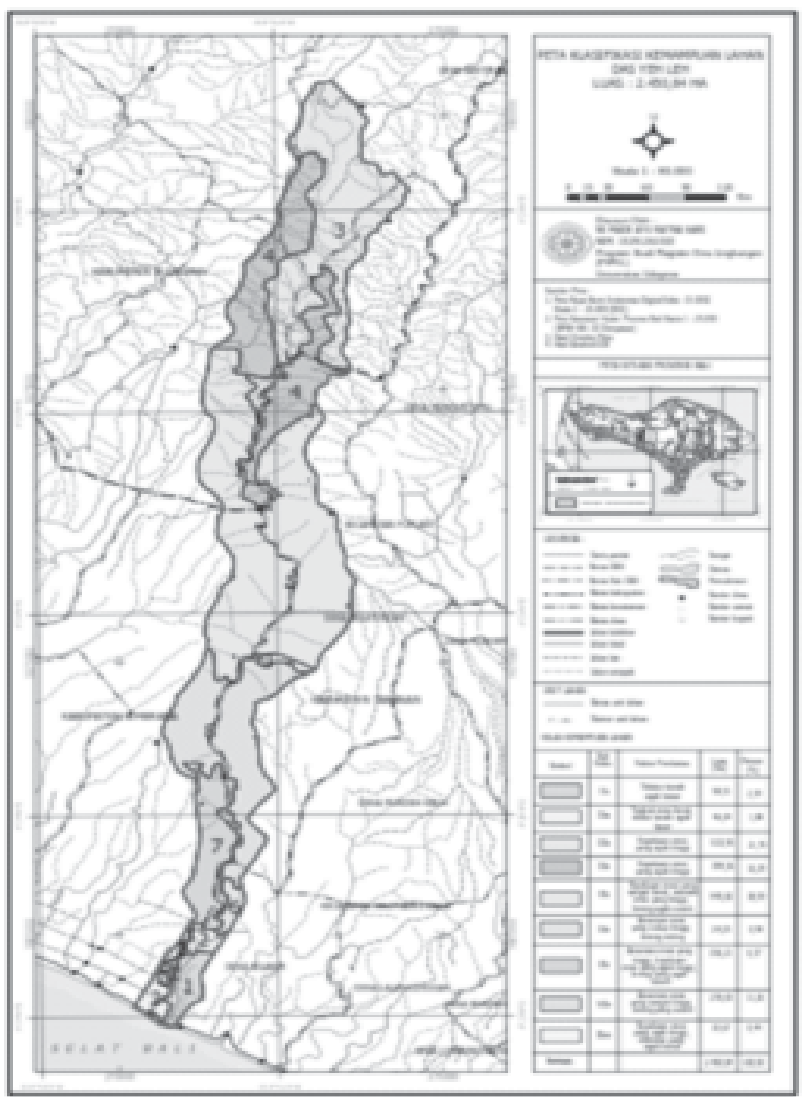

Gambar 2.

Peta Kelas Kemampuan Lahan DAS Yeh Leh 
menurut kontur pada kemiringan > $20 \%$. Penurunan nilai erosi terjadi setelah dilakukannya tindakan konservasi tanah dari nilai erosi sebesar 98,00 ton/ha/tahun menjadi 8,82 ton/ha/tahun sehingga nilai tersebut sudah menjadi lebih kecil dari nilai erosi yang ditoleransikan yaitu 27,02 ton/ha/ tahun.

Pada unit lahan 5 penggunaan lahan saat ini adalah perkebunan dengan serasah sedang dan tindakan konservasi tanah berupa teras tradisional dengan kemiringan lereng $44 \%$. Alternatif perencanaan konservasi tanah dan air dilakukan dengan mengubah faktor pengelolaan tanaman menjadi kebun campuran dengan tajuk bertingkat, penutup tanah bervariasi dengan kerapatan tinggi. Untuk faktor pengelolaan tanah yaitu dari teras tradisional menjadi teras bangku konstruksi sedang dan penanaman strip rumput. Penurunan nilai erosi terjadi setelah dilakukannya tindakan konservasi tanah dari nilai erosi sebesar 866,35 ton/ha/tahun menjadi 2,97 ton/ha/tahun sehingga nilai tersebut sudah menjadi lebih kecil dari nilai erosi yang ditoleransikan yaitu 29,17 ton/ha/tahun.

Pada unit lahan 9 penggunaan lahan saat ini adalah perkebunan dengan serasah tinggi dan tindakan konservasi tanah berupa teras tradisional dengan kemiringan lereng $5 \%$. Alternatif perencanaan konservasi tanah dan air dilakukan dengan mengubah faktor pengelolaan tanaman menjadi perkebunan dengan kerapatan tinggi. Untuk faktor pengelolaan tanah yaitu dari teras tradisional menjadi teras bangku konstruksi sedang dan penanaman dilakukan menurut kontur pada kemiringan 9 - $20 \%$. Penurunan nilai erosi terjadi setelah dilakukannya tindakan konservasi tanah dari nilai erosi sebesar 63,01 ton/ha/tahun menjadi 17,72 ton/ha/tahun sehingga nilai tersebut sudah menjadi lebih kecil dari nilai erosi yang ditoleransikan yaitu 30,44 ton/ha/tahun.

Alternatif penerapan tindakan konservasi pengelolaan tanah pada unit lahan $2,3,4,5$ dan 9 diharapkan dapat menekan tingkat erosi yang terjadi, sehingga nilai erosi yang terjadi bisa sama atau lebih kecil dari erosi yang dapat ditoleransikan (T). Dengan penutupan lahan yang sesuai serta diimbangi dengan tindakan konservasi tanah yang tepat, diharapkan dapat menekan laju erosi yang terjadi.

\subsection{Klasifikasi Kemampuan Lahan}

Dalam menentukan klasifikasi kemampuan lahan menggunakan metode Arsyad (1989) yaitu dengan menggolongkan kelas kemampuan lahan berdasarkan nilai dari faktor pembatas yang dimiliki masing - masing unit lahan, yang selanjutnya diklasifikasikan berdasarkan sub kelas kemampuan lahan. Adapun faktor pembatas yang diperhitungkan yaitu kemiringan lereng, kepekaan erosi, tingkat bahaya erosi, kedalaman efektif, tekstur, permeabilitas, drainase, batuan, dan ancaman banjir suatu lahan, yang selanjutnya disesuaikan dengan kriteria klasifikasi kemampuan lahan.

Yang termasuk kelas kemampuan lahan II adalah : a)kemampuan lahan kelas IIs yaitu unit lahan 1 dengan faktor pembatas berupa tekstur tanah yang kasar dengan luas 58,51 ha yaitu di Desa Selabih, Kecamatan Selemadeg Barat, Kabupaten Tabanan. b) Kemampuan lahan kelas IIes yaitu unit lahan 2 dengan faktor pembatas tingkat erosi yang berat dan tekstur tanah yang agak kasar dengan luas 46,04 ha yaitu di Desa Pengeragoan, Kecamatan Pekutatan, Kabupaten Jembrana dan desa Selabih, Kecamatan Selemadeg Barat, Kabupaten Tabanan. c) Kemampuan kelas lahan IIew yaitu unit lahan 9 dengan faktor pemberat yaitu kepekaan erosi yang agak tinggi dan drainase yang agak buruk dengan luas 10,67 ha yaitu di Desa Pengeragoan, Kecamatan Pekutatan, Kabupaten Jembrana

Kelas kemampuan lahan IIIeadalah unit lahan 3 dengan faktor pembatas berupa kepekaan erosi yang agak tinggiseluas 533,95 ha yaitu meliputi : 1) Desa Pengeragoan, Kecamatan Pekutatan, Kabupaten Jembrana, 2) Desa Bongancina, 3) Desa Puncaksari,

Tabel 5. Kelas Kemampuan Lahan di DAS Yeh Leh

\begin{tabular}{|c|c|c|c|c|}
\hline $\begin{array}{l}\text { No Unit } \\
\text { Lahan }\end{array}$ & $\begin{array}{c}\text { Kelas } \\
\text { Kemampuan } \\
\text { Lahan }\end{array}$ & $\begin{array}{c}\text { Sub Kelas } \\
\text { Kemampuan } \\
\text { Lahan }\end{array}$ & $\begin{array}{c}\text { Faktor } \\
\text { Pembatas }\end{array}$ & Keterangan \\
\hline 1 & $\|$ & IIs & Tekstur & Tekstur tanah agak kasar \\
\hline 2 & II & lles & Erosi dan tekstur & Tingkat erosi yang berat dan tekstur tanah agak kasar \\
\hline 3 & III & Ille & Erosi & Kepekaan erosi yang agak tinggi \\
\hline 4 & IV & IVe & Erosi & Kepekaan erosi yang agak tinggi \\
\hline 5 & VI & Vle & Erosi & $\begin{array}{l}\text { Kepekaan erosi yang sangat beratdan acaman erosi yang tinggi karena lereng } \\
\text { agak curam }\end{array}$ \\
\hline 6 & IV & IVe & Erosi & Ancaman erosi yang cukup tinggi karena lereng miring \\
\hline 7 & VI & Vle & Erosi & $\begin{array}{l}\text { Ancaman erosi yang tinggi dan kepekaan erosi yang agak tinggi karena lereng } \\
\text { yang agak curam }\end{array}$ \\
\hline 8 & VII & VIle & Erosi & Ancaman erosi yang sangat tinggi karena lereng yang curam. \\
\hline 9 & II & Ilew & Erosi dan drainase & Kepekaan erosi yang agak tinggi dan drainase yang agak buruk \\
\hline
\end{tabular}


serta 4) Desa Tista, Kecamatan Busungbiu, Kabupaten Buleleng. Kelas kemampuan lahan IV adalah unit lahan 4dan 6 dengan faktor pembatas berupa kepekaan erosi yang beratseluas 423,61 hayaitu meliputi :1) Desa Belatungan, 2) Desa Puncaksari, 3) Desa Tista, 4) Desa Bongancina, Kecamatan Busungbiu, Kabupaten Buleleng serta 5) Desa Selabih, Kecamatan Selemadeg Barat, Kabupaten Tabanan.

Kelas kemampuan lahan VI adalah unit lahan 5dan 7 dengan faktor pembatas berupa kepekaan erosi yang beratseluas 1.102,03 ha yaitu meliputi : 1) Desa Pengeragoan, Kecamatan Pekutatan, Kabupaten Jembrana serta 2) Desa Belatungan, dan 3) Desa Tista Kecamatan Busungbiu, Kabupaten Buleleng. Kelas kemampuan lahan VII adalah unit lahan 8 dengan faktor pembatas berupa ancaman erosi yang tinggi seluas 276,03 ha yaitu meliputi : 1) Desa Belatungan, Kecamatan Busungbiu, Kabupaten Buleleng, 2) Desa Pengeragoan, Kecamatan Pekutatan, Kabupaten Jembrana, dan 3) desa Selabih, Kecamatan Selemadeg Barat, Kabupaten Tabanan.

\subsection{Arahan Penggunaan Lahan}

Metode skoring untuk arahan penggunaan lahan dipengaruhi oleh 3 faktor yaitu, faktor lereng lapangan, faktor kepekaan jenis tanah terhadap erosi dan faktor intensitas curah hujan harian rata - rata. Hasil penjumlahan dari faktor lereng lapangan, faktor kepekaan jenis tanah terhadap erosi dan faktor intensitas curah hujan harian rata - rata tersebut akan menentukan arahan penggunaan lahan pada masing - masing unit lahan (Tabel 5). Berdasarkan hasil penelitian, lahan di luar kawasan hutan dengan penggunaan lahan sebagai kawasan budidaya tanaman semusim (unit lahan 1). Pada unit lahan
2, 3, 4, dan 9 yaitu sebagai luar kawasan hutan dengan fungsi budidaya tanaman tahunan. Untuk unit lahan 5 yaitu di luar kawasan hutan sebagai kawasan penyangga. Untuk kawasan hutandengan fungsi hutan lindung pada unit lahan 6,7 , dan 8 .

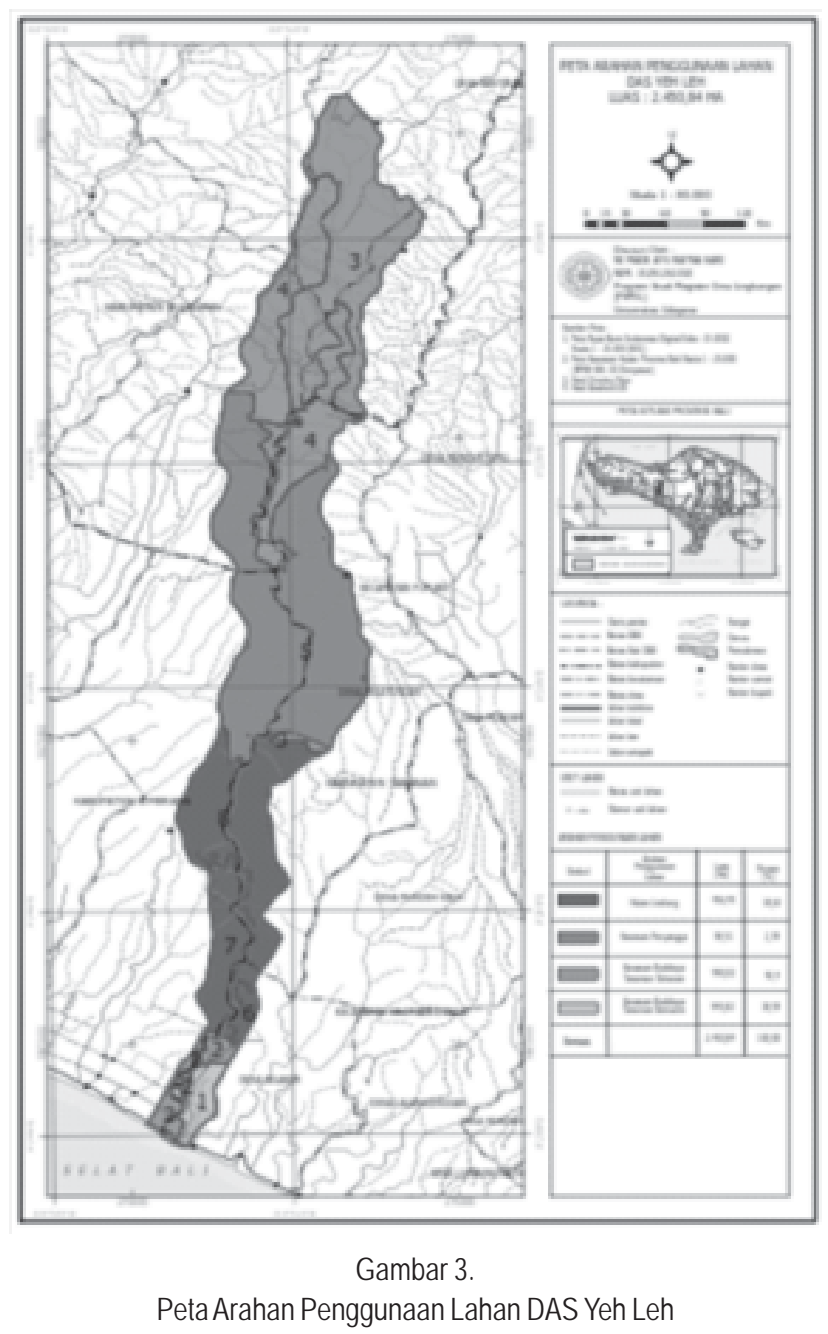

Tabel 6. Arahan Penggunaan Lahan di DAS Yeh Leh

\begin{tabular}{|c|c|c|c|c|c|c|c|c|c|}
\hline \multirow[t]{2}{*}{$\begin{array}{l}\text { No Unit } \\
\text { Lahan }\end{array}$} & \multicolumn{2}{|c|}{$\begin{array}{l}\text { Kemiringan } \\
\text { lereng }\end{array}$} & \multicolumn{2}{|c|}{$\begin{array}{l}\text { Jenis Tanah } \\
\text { Menurut } \\
\text { Kepekaannya }\end{array}$} & \multicolumn{2}{|c|}{$\begin{array}{l}\text { Intensitas } \\
\text { Hujan Harian } \\
\text { Rata-Rata }\end{array}$} & \multirow[t]{2}{*}{$\begin{array}{l}\text { Total } \\
\text { Skor }\end{array}$} & \multicolumn{2}{|c|}{ Arahan Penggunaan Lahan } \\
\hline & (\%) & Skor & Jenis & Skor & $\mathrm{mm} /$ hari & Skor & & $\begin{array}{c}\text { Dalam Kawasan } \\
\text { Hutan }\end{array}$ & $\begin{array}{l}\text { Luar Kawasan } \\
\text { Hutan }\end{array}$ \\
\hline 1 & 7 & 20 & Latosol & 30 & 18,47 & 20 & 70 & - & $\begin{array}{l}\text { Kawasan budidaya } \\
\text { tanaman semusim }\end{array}$ \\
\hline 2 & 5 & 20 & Latosol & 30 & 18,47 & 20 & 70 & - & $\begin{array}{c}\text { Kawasan budidaya } \\
\text { tanaman tahunan }\end{array}$ \\
\hline 3 & 13 & 40 & Latosol & 30 & 18,47 & 20 & 90 & - & $\begin{array}{l}\text { Kawasan budidaya } \\
\text { tanaman tahunan }\end{array}$ \\
\hline 4 & 27 & 60 & Latosol & 30 & 18,47 & 20 & 110 & - & $\begin{array}{c}\text { Kawasan budidaya } \\
\text { tanamantahunan }\end{array}$ \\
\hline 5 & 44 & 80 & Latosol & 30 & 18,47 & 20 & 130 & - & Kawasan penyangga \\
\hline 6 & 24 & 60 & Latosol & 30 & 18,47 & 20 & 110 & Hutan lindung & - \\
\hline 7 & 43 & 80 & Latosol & 30 & 18,47 & 20 & 130 & Hutan lindung & - \\
\hline 8 & 56 & 100 & Latosol & 30 & 18,47 & 20 & 150 & Hutan lindung & - \\
\hline 9 & 5 & 20 & Regosol & 75 & 18,47 & 20 & 115 & & $\begin{array}{l}\text { Kawasan budidaya } \\
\text { tanamantahunan }\end{array}$ \\
\hline
\end{tabular}


Untuk kategori penggunaan lahan luar kawasan hutan dapat dibagi menjadi empat yaitu: kawasan lindung, kawasan penyangga, kawasan budidaya tanaman tahunan, dan kawasan budidaya tanaman semusim. Untuk arahan penggunaan lahan luar kawasan hutan yaitu kawasan budidaya dan kawasan penyangga. Pada unit lahan 1 seluas 58,51 ha $(2,39 \%)$ di Desa Selabih, Kecamatan Selemadeg Barat, Kabupaten Tabanan dengan total skor 70termasuk pada kategori kawasan budidaya tanaman semusim yaitu sawah irigasi dengan kemiringan lereng $7 \%$. Jenis tanaman bisa divariasi, misalnya padi, jagung, melon, semangka, dan kacang-kacangan. Melindungi tanah dari kerusakan secara langsung juga penting dilakukan yaitu dengan penggunaan sisa-sisa tanaman sebagai penutup tanah serta pembuatan teras dengan konstruksi baik agar permukaan tanah tidak mudah tergerus air hujan maupun aliran permukaan.

Pada unit lahan 2, 3, 4, dan 9 seluas 990,02 ha (40,40\%) dengan jumlah skor $70-115$ dengan kemiringan $5 \%-27 \%$ termasuk kawasan budidaya tanaman tahunan yang pada umumnya berupa kebun campuran tersebar di wilayah : 1) Desa Pengeragoan, Kecamatan Pekutatan, Kabupaten Jembrana, 2) desa Selabih, Kecamatan Selemadeg Barat, Kabupaten Tabanan, 3) Desa Bongancina, 4) Desa Puncaksari, 5) Desa Tista, Kecamatan Busungbiu, Kabupaten Buleleng serta 6) Desa Belatungan, Kecamatan Pupuan, Kabupaten Tabanan. Penanaman sebaiknya dilakukan menurut kontur disesuaikan dengan kemiringan lahan. Pada unit lahan 5 seluas 945,82 ha $(38,59 \%)$ dengan jumlah skor 130 dan kemiringan $44 \%$ termasuk kawasan penyangga yang merupakan wilayah yang berada di antara kawasan lindung dan kawasan budidaya dengan fungsi lindung, budidaya, dan produksi terbatas baik itu perkebunan campuran, tanaman keras, dan jenis lainnya. Kawasan ini tersebar di : 1) Desa Belatungan, Kecamatan Pupuan, Kabupaten Tabanan, 2) Desa Tista, Kecamatan Busungbiu, Kabupaten Buleleng, dan 3) Desa Pengeragoan, Kecamatan Pekutatan, Kabupaten Jembrana.

Kawasan dalam hutan untuk di wilayah penelitian yaitu pada unit lahan 6,7 , dan 8 seluas 456,49 ha yang meliputi : 1) Desa Selabih, Kecamatan Selemadeg Barat, Kabupaten Tabanan, 2) Desa Pengeragoan, Kecamatan Pekutatan, Kabupaten Jembrana, dan 3) Desa Belatungan, Kecamatan Busungbiu, Kabupaten Buleleng.. Kawasan hutan ini dikategorikan sebagai hutan lindung dengan fungsi pokok sebagai perlindungan sistem penyangga kehidupan, mengatur tata air, mencegah banjir, mengendalikan erosi serta memelihara kesuburan tanah. Kawasan ini dikelola oleh Dinas Kehutanan Provinsi Bali, UPT Resort Pengelolaan Hutan Bali Barat yang berlokasi di desa Gilimanuk, Kecamatan Melaya, Kabupaten Jembrana. Melalui pengamatan di lapangan, pada unit lahan tersebut, keberadaan hutannya masih sangat alami dengan penutupan tajuk yang rapat, keadaan serasah tinggi, pelindung sumber mata air yang berada di sekitarnya serta harus dijaga kelestariannya sebagai daerah tangkapan air hujan. Berdasarkan hasil penelitian, pada unit lahan 6,7 , dan 8 untuk faktor kemiringan lereng, jenis tanah menurut kepekaannya, serta intensitas hujan rata-rata memiliki jumlah skor antara 110 - 150 yaitu masih kurang dari jumlah skor penetapan sebagai dalam kawasan sebagai hutan lindung yaitu 175, namun diihat dari pengamatan langsung di lapangan bahwa pada unit lahan tersebut memiliki fungsi perlidungan tata air serta perlindungan tanah dari erosi dan pengikisan tanah oleh air hujan pada beberapa lokasi yang memiliki kemiringan $>45 \%$.

\section{SIMPULAN DAN SARAN}

\subsection{Simpulan}

Berdasarkan hasil penelitian yang dilakukan di wilayah Daerah Aliran Sungai Yeh Leh, maka kesimpulannya adalah sebagai berikut :

1. Wilayah Daerah Aliran Sungai Yeh Leh, tingkat erosi yang terjadi termasuk pada kategori ringan sampai dengan sangat berat. Tingkat erosi sangat ringan seluas 515 ha $(21,01 \%)$ dengan penggunaan lahan berupa sawah irigasi, hutan, dan perkebunan. Tingkat erosi berat seluas 990,02 ha (40,40\%) dengan penggunaan lahan berupa perkebunan. Sedangkan untuk tingkat erosi sangat berat seluas 945,82 ha $(38,59 \%)$ dengan penggunaan lahan berupa perkebunan.

2. Pada unit lahan di wilayah Daerah Aliran Sungai Yeh Leh yang memiliki nilai prediksi erosi melebihi nilai erosi yang diperkenankan, alternatif tindakan konservasi tanah dan air yaitu berupa perkebunan dengan serasah sedang sampai serasah tinggi, pembuatan teras bangku dengan konstruksi sedang hingga baik, penanaman dilakukan menurut kontur disesuaikan dengan kemiringan lahan, serta penanaman strip rumput.

3. Klasifikasi kemampuan lahan di wilayah Daerah Aliran Sungai Yeh Leh terdiri dari 5 kelas kemampuan lahan yaitu kelas II seluas 115,22 ha $(4,70 \%)$, kelas III seluas 533,95 ha $(21,79 \%)$, kelas IV seluas 423,61 (17,28\%), kelas VI seluas $1.102,03$ ha (44,97\%), dan kelas VII seluas 276,03 ha $(11,26 \%)$. Dengan faktor pembatas yaitu tekstur tanah, erosi, dan drainase.

4. Arahan Penggunaan lahan di wilayah Daerah aliran Sungai Yeh Leh untuk kawasan dalam hutan yaitu sebagai hutan lindung seluas 456,49 ha $(18,63 \%)$. Arahan penggunaan lahan di luar kawsan hutan berupa kawasan budidaya tanaman semusim seluas 58,51 ha (2,39\%), kawasan budidaya tanaman tahunan seluas 
990,02 ha (40,40\%) dan kawasan penyangga seluas $945,82(38,59 \%)$.

\subsection{Saran}

Berdasarkan penelitian yang dilakukan di daerah aliran sungai Yeh Leh, maka dapat diajukan saran sebagai berikut :

1. Lahan dengan nilai erosi yang melebihi nilai erosi yang ditoleransikan dapat dibuatkan alternatif penggunaan lahanyang dapat dilakukan untuk membantu mengendalikan erosi yang terjadi, yaitu dengan menambahkan serasah dan mulsa melalui peningkatan jumlah tanaman dan kombinasi jenis tanaman agar permukaan tanah tidak terkena air hujan secara langsung maupun terjadinya aliran permukaan pada saat musim penghujan. Di samping itu, tindakan konservasi pengelolaan tanah juga diperlukan, seperti misal membuat teras yang memiliki konstruksi baik. Dengan tetap mengacu pada CP maksimum pada setiap unit lahan sehingga nilai erosi dapat dikendalikan agar nilai prediksi erosi dapat lebih kecil atau sama dengan nilai erosi yang ditoleransikan.

2. Dengan diketahuinya klasifikasi kemampuan lahan suatu wilayah maka dapat dilakukan pemanfaatan lahan yang tepat dan benar agar tidak menimbulkan kerusakan pada lingkungan

3. Lahan yang nilai prediksi erosinya tidak melampaui nilai erosi yang ditoleransikan harus tetap dijaga dan dilestarikan baik melalui pengelolaan tanaman maupun pengelolaan tanah yang sesuai. Apabila memungkinkan erosi yang terjadi dapat diperkecil dengan mempertahankan dan memperbaiki pengelolaan tanaman dan konservasi tanah yang telah dilakukan.

\section{DAFTAR PUSTAKA}

Adnyana, I. W.S, dan A. R. As-syakur. 2011. Kelas Kemampuan Lahan dan Arahan Penggunaan Lahan Provinsi Bali. Dalam : Adnyana, I. W. S., Arthana, I. W., dan As-syakur, A. R., (editors). Perubahan Penggunaan Lahan dan Daya Dukung Lingkungan. Udayana Univesity Press dan Pusat Penelitian Lingkungan Hidup (PPLH). Universitas Udayana. Denpasar, Hal. 52-64.

Arsyad, S. 1989. Konservasi Tanah dan Air. Bogor: IPB Press.

Asdak, C. 2010. Hidrologi dan Pengelolaan Daerah Aliran Sungai. Yogyakarta: Gadjah Mada University Press.

Bols. P. L. I978. The Iso-erdent Map Of Java and Madura. Report On Belgian Technical Assistance Project ATA 105. SRI Bogor.

Surat Keputusan (SK) Menteri Pertanian Nomor 837/ Kpts/Um/8/1980 dan Nomor 683/Kpts/Um/8/ 1981 tentang Kriteria dan tata cara penetapan hutan lindung dan hutan prodiksi.

Tan, K.H. 1991. Dasar - Dasar Kimia Tanah. Terjemahan Goenadi, D.H. Gajah Mada University Press. Yogyakarta.

Wischmeir, W. H. and D. D. Smith. 1978. Predicting Rainfall Erosion Lossess: A Guide to Conservation Planning. USDA Agric. Handbook No.537. Washington DC. 